\title{
Mapping past land use in Europe for climate modeling
}

\author{
Rosie R. Bishop ${ }^{1}$ and Marc Vander Linden ${ }^{2}$ \\ Hemmenhofen, Germany, 28-30 January 2019
}

The PAGES LandCover6k (pastglobalchanges. org/landcover6k) Europe group workshop, hosted by Dr. Elena Marinova at the Research Center for Wetland Archaeology in Hemmenhofen, Germany, was attended by an interdisciplinary group of European researchers, which included archaeobotanists, zooarchaeologists, landscape archaeologists, and environmental scientists.

The workshop built on discussions from two earlier LandCover6k Europe group workshops in 2018 (both in Barcelona, Spain) and research that had been undertaken by the group over the past year.

The workshop focused on several key themes:

- Evaluating the project methodologies for mapping land use.

- Evaluating initial regional European landuse maps for the period 4250-3750 cal BCE (6000 BP).

- Refining definitions of land use for global mapping and the categories for the accompanying database of sites.

- Data ownership and plans for future publications from the project.

Day one involved a series of presentations from different participants. The workshop began with a welcome address from Dr. Renate Ebersbach, the director of the research center. Following this, the European group coordinators, Dr. Nicki Whitehouse (University of Plymouth, UK), Prof. Marco Madella (UPF, Barcelona, Spain) and Dr. Ferran Antolin (University of Basel, Switzerland), updated the group on progress since the previous meeting and introduced the agenda for the workshop.

Dr. Oliver Boles (University of Pennsylvania, USA) presented the definitions of land use that will be used for mapping, and there was discussion regarding the standardized categories to be used for the database of site information that will accompany the maps. It is necessary to develop standardized definitions of different types of land use (e.g. hunter-gathering, pastoralism) to enable global comparisons to be made (Morrison et al. 2018).

This discussion was followed by a series of papers reviewing methodological issues for modeling past land use. Dr. Marc Vander Linden (University of Cambridge, UK) updated the group on the site mapping that had been undertaken since the previous meeting and explained the decision to use kernel densities to map European land use. Prof. Sandy Harrison (University of Reading, UK) then outlined the types of information needed as input for climate models and how archaeologists can provide relevant

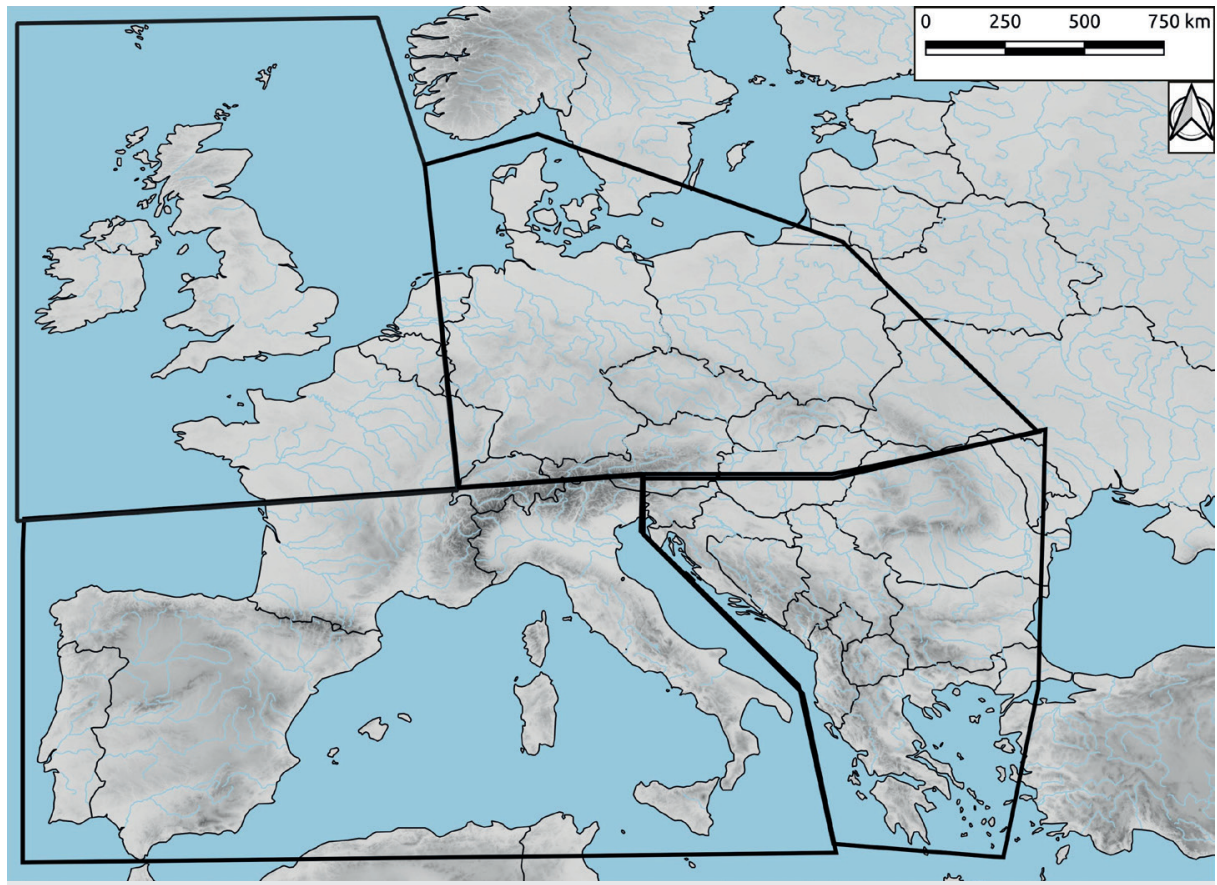

Figure 1: Distribution of the regional sub-groups (Northwest Europe, Northern Europe, Southeast Europe,

Southwest Europe). data or improve existing estimates based on expert knowledge. Key information modelers require include: the dates of first agriculture and percentage of agricultural land, estimates of population growth, how much biomass was removed (percentage of different crops and domestic animals, as well as mass density in $\mathrm{kg} / \mathrm{m}^{2}$ of wood and nuts harvested), and the mix of $\mathrm{C} 3$ versus $\mathrm{C} 4$ crop plants grown. Finally, Dr. Tilman Baum (University of Basel, Switzerland) discussed a modeling land-use case study in the Alpine Foreland using agent-based simulations.

In the second part of the meeting, the preliminary land-use maps generated at a previous meeting in May 2018 (Whitehouse et al. 2018) were evaluated by regional sub-groups (Northwest Europe, Northern Europe, Southeast Europe, Southwest Europe; Fig. 1) to establish data gaps and errors. The initial maps were constructed using expert knowledge, together with a European database of radiocarbon dates collated by Dr. Marc Vander Linden and subsequent data collections by the group.

Day two focused on refining the standardized categories that will be used in the database of sites to accompany the maps, and discussing the plans for papers that will be produced from the project.

\section{Future research}

The project team is currently working to fill in gaps in datasets. The aim is to produce initial land-use maps using basic top-level classifications of land use (e.g. hunter-gathering/ agriculture) to allow climate modelers to test whether human impacts on land cover in prehistory were large enough to influence climate change. The datasets will be increasingly refined and used to produce more detailed maps that will incorporate information on different hunting and gathering, farming, and fuel-procurement strategies. It is hoped that the final output of the project will prove useful for both the modeling and archaeological communities.

\section{AFFILIATIONS}

'Department of Archaeology, Durham University, UK 2Department of Archaeology, University of Cambridge, UK

\section{CONTACT}

Rosie Bishop: rosie@rosiebishop.com

\section{REFERENCES}

Morrison KD et al. (2018) PAGES Mag 26: 8-9

Whitehouse N et al. (2018) PAGES Mag 26: 90 